\title{
The State of Elder Care in Mexico
}

\author{
Luis Miguel Gutiérrez Robledo • Mariana López Ortega • \\ Victoria Eugenia Arango Lopera
}

Published online: 27 September 2012

(C) Springer Science+Business Media, LLC 2012

\begin{abstract}
Nine percent (10.05 million) of the Mexican population is over 60 years old, with an annual growth during the last decade of close to $4 \%$, and a female aging pattern. Members of this group live predominantly in urban areas $(74 \%)$, are married or have a partner $(60 \%)$, and generally have very low levels of education. The principal causes of morbidity, based on official registers, are respiratory infections, peptic disease, hypertension and diabetes, However, other sources of health data show that $43 \%$ of the elderly population had had at least one fall in the past year, and $43 \%$ experienced symptoms of depression. In addition, $10 \%$ were reported to have cognitive decline. The principal reported causes of mortality are diabetes, and cardiovascular and pulmonary diseases. Health services and users are divided according to the health institution that provides the service. There are three main providers: 1) social security institutions, 2) public services offered by the Ministry of Health, and 3) private sector providers. In 2008, the National Institute on Aging (INGER) was founded in Mexico. In the next five years the Institute will focus on development, operation and evaluation of the new elderly health care system and gerontological/geriatric education, with a strong evidence-based perspective. In addition, it will continue the development of biological, clinical, technological and biomedical research. Mexico should continue to build programs and policies with a humans rights perspective and oriented to the adaption of health care the addresses the needs of the elderly. Specifically, it should be focused on providing the elderly with primary care, education, and the resources to avoid functional dependency, and enhance
\end{abstract}

\footnotetext{
L. M. G. Robledo $(\bowtie) \cdot$ M. L. Ortega • V. E. A. Lopera Instituto Nacional de Geriatría, Periférico Sur 2767 colonia San Jerónimo Lídice delegación Magdalena Contreras, 10200 México, DF, Mexico

e-mail: luis.gutierrez@salud.gob.mx
}

active and healthy aging, as well as on increasing access to an adequate information system and specialized training for human resources that is dedicated to care for the elderly.

Keywords Health system · Aging policies · Mexico · Elderly $\cdot$ Health care

\section{Introduction}

The average life expectancy of the elderly in Mexico is approaching that of Europe or North America, at about 72 years. Moreover, $9 \%$ of the Mexican population is over 60 years old, with an annual growth in the last decade of close to $4 \%$. In two decades or less, this segment of the population will reach 20 million people; however, even with just half of that population, the country is not currently equipped to face this problem. There are 87 men for every 100 women, and the life expectancy at 60 years old is estimated at 22.9 years for women, and 20.9 for men. This group of the population lives predominantly in urban areas ( $74 \%)$, is married or has a partner $(60 \%)$, and has very low levels of educational attainment, with $50 \%$ having only completed primary/elementary school and $27.2 \%$ having never attended formal education. Mexico has a dependency ratio of $10 / 100[1,2]$.

As with most Latin American countries, Mexico is experiencing a "mixed" epidemiological transition with a sharp increase in the prevalence of chronic diseases and a marked decrease in communicable diseases in some areas, while still suffering from moderate or high incidence of the latter in some regions of the country. In addition, the country lacks strong institutional systems - whether public or privatethat can adequately respond to the changing social and health care demands from an elderly population. Within the country, differences among states and regions, and 
between more urban and rural areas, are sharp and mainly correlate with lags in economic growth and marked inequalities in socioeconomic development.

Health expenditure as a part of Gross Domestic Product (GDP) was $6.2 \%$ in $2010,47.3 \%$ of which came from public sources. While the number of doctors per capita increased substantially over the past two decades, reaching 2 practicing doctors per 1,000 in 2010 , the doctor-topopulation ratio still remains far behind the Organization for Economic Cooperation and Development (OECD) average of 3.1. Regarding nurses, for the same year, there were 2.5 nurses per 1,000 persons, and the number of hospital beds for curative care was 1.6 per 1,000 persons [3] (OECD Health Data 2012).

\section{Morbidity and Mortality Profile in Elderly Mexican People}

The aging pattern in Mexico, as in the rest of the world is favors longevity in women: in the age group of 60-74 years there are 112 females to every 100 males and in the old oldest group (over 85 years), there are 135 females to every 100 males. Moreover, Mexico has a high number of females between the ages of 40-59 years old $(11,450,938)$ (INEGI 2010), which means that if sanitary programs and policies do not focus on avoidance of functional dependence more than the avoidance of chronic disease incidence, in several years the social or sanitary systems will not be able to sustainably serve these citizens. On the other hand, aging males are impacted by special conditions, such as accidents, suicides, addictions, and lower survival and higher migration rates [4].

The primary morbidity causes in elderly Mexicans, according to official registers, are respiratory infections, peptic disease, hypertension and diabetes [5]. However, other sources of data such as MHAS (Mexican Health and Aging Survey, 2003), showed that $43 \%$ of the elderly population had suffered at least one fall in the year prior and $43 \%$ had also experienced symptoms of depression; these were not registered in the official system. In addition, $10 \%$ had cognitive decline [6], while the prevalence of Alzheimer's disease is $6.1 \%$ for those over the age of 60 , with an incidence of 27.3/1000 persons per year [7].

Over $50 \%$ of subjects 65 years of age or older are reported to have at least one chronic disease, and up to $20 \%$ of this age range has at least two $[8,9]$.

In the last Mexican census (2010), $21 \%$ of respondents over the age of 60 reported having at least one disability; by 2000 , those reporting the highest disability rates were over 70 years old, a group that was equal to $17 \%$. In the last census, this percentage has moved to the right, meaning that the oldest-old (over 85 years), is the group with the most need for help in activities of daily living [1]. Additionally, official data shows that the elderly are the group with the greatest health care use: as shown by the numbers from the Mexican Institute of Social Security (IMSS, the biggest affiliation system in Mexico), in 2002 more than $30 \%$ of clinic visits were for adults over 60 years old with the principal causes being hypertension, diabetes, infectious diseases and osteoarthritis; the majority were without adequate care and experienced functional impairment as a consequence.

On the other hand, the mortality profile has changed substantially in the last century. In the 1920's, the Mexican population was diminished by war, flu epidemics and migration, and only $5 \%$ reached the age of 75 ; in contrast, today it is estimated that $75 \%$ of the population will live to at least 75 years. The principal reported mortality causes are diabetes, cardiovascular and pulmonary diseases [10].

In 2010, 592,018 deaths were registered, $62.4 \%$ of these were for adults aged more than 60 years old $(50.5 \%$ were males). The National Health Information System (SINAIS) cites the three major causes of death in elderly people as heart disease, diabetes and cancer. In a specific case, again from IMMS, in the same year $5 \%$ of the reported deaths were in children under 5 years old, and close to $60 \%$ were in people over 60 years (the opposite was seen until 35 years ago). Close to $75 \%$ of deaths were from reasons other than transmissible diseases [11].

An analysis of death causes in elderly people, taking into account a Social Inequalities Index (SII), found no differences between sex or age (Velasco-Roldán et al, personal communication). However, there are important socioeconomic differences: elderly people in small villages, and in more disadvantaged conditions - in terms of the SIIwere found to suffer a higher number of deaths from undernutrition and unknown causes. In contrast, in areas with the lowest SII - that is, more advantaged localities - cardiovascular diseases remain the cause of death with the highest incidence rate, as in developed countries. It is important to note that "senility" was a probable cause of death in close to $6 \%$ of total deaths in people aged over 85 years.

\section{Health Care System}

In terms of health services and health care provision, the older population technically has the same access to health services as any other age group of the population, through the Mexican Health System, but this system has been highly segmented since its creation. Health services and users are divided according to the health institution that provides the service (See Table 1). There are three main providers: a) social security institutions, b) public services offered by the Ministry of Health, and c) the private sector. They offer 
Table 1 Main characteristics of the Mexican Health System

\begin{tabular}{|c|c|c|c|}
\hline Sector/Institution & Sector of population served & Funding/ Finance scheme & Services provided \\
\hline \multirow[t]{2}{*}{$\begin{array}{l}\text { Ministry of Health at federal } \\
\text { and state level }\end{array}$} & Seguro Popular & $\begin{array}{l}\text { Public funds from general taxes. } \\
\text { State level ministries participate } \\
\text { through a compulsory matching of } \\
\text { some public funds, infrastructure } \\
\text { and human resources }\end{array}$ & $\begin{array}{l}\text { Package of comprehensive health } \\
\text { services. Different service packages } \\
\text { according to age group, target } \\
\text { indicator (maternal health), or } \\
\text { disease (NCCDs, CA, etc.) }\end{array}$ \\
\hline & Uninsured & Public funds from general taxes & $\begin{array}{l}\text { Ambulatory care at community health } \\
\text { centers throughout the country, } \\
\text { second and third level hospitals, and } \\
\text { specialized interventions at general } \\
\text { and specialized hospitals }\end{array}$ \\
\hline IMSS & $\begin{array}{l}\text { Insured through an employer; } \\
\text { covers individual and their } \\
\text { dependents (children or parents) }\end{array}$ & $\begin{array}{l}\text { Three-way funding scheme: } \\
\text { a) Public funds from general taxes, } \\
\text { b) Fee from workers/employees, } \\
\text { c) Fee from employers } \\
\text { A second option of voluntary } \\
\text { affiliation, irrespective of working } \\
\text { status, to either a health services- } \\
\text { only scheme or a full-benefit scheme } \\
\text { was recently implemented. This } \\
\text { option now represents approximately } \\
5 \% \text { of all insured citizens }\end{array}$ & $\begin{array}{l}\text { IMSS has a package of coverage } \\
\text { schemes, the most important of which } \\
\text { are: a) sickness and maternity } \\
\text { insurance, b) disability, unemployment, } \\
\text { old age, and death insurance, c) labor } \\
\text { risk insurance, and d) day care centers. } \\
\text { Includes ambulatory care clinics, } \\
\text { specialization clinics and hospitals }\end{array}$ \\
\hline ISSSTE & $\begin{array}{l}\text { Insurance comes from employment } \\
\text { in federal/state government } \\
\text { institutions }\end{array}$ & $\begin{array}{l}\text { Three-way funding scheme: employer, } \\
\text { employee, and public funds from } \\
\text { general taxes. The government as the } \\
\text { employer covers some of this fee, the } \\
\text { public funds another portion, and the } \\
\text { rest is provided by the employee }\end{array}$ & $\begin{array}{l}\text { Package of medical insurance, } \\
\text { disability, old age and } \\
\text { unemployment schemes }\end{array}$ \\
\hline Private sector & $\begin{array}{l}\text { Those with no social security or } \\
\text { public insurance (users of private } \\
\text { consultant services) and those } \\
\text { with private insurance schemes }\end{array}$ & $\begin{array}{l}\text { Out-of pocket payments, health } \\
\text { insurance policies for major } \\
\text { interventions and ambulatory care } \\
\text { based on co-payments }\end{array}$ & $\begin{array}{l}\text { Mainly specialist consultant and } \\
\text { hospital services }\end{array}$ \\
\hline
\end{tabular}

Updated and modified from original table in Lopez-Ortega et al. (2007), using Census 2010 data: INEGI (2010). Tabulados Básicos, Censo de Población y Vivienda 2010. México. INEGI

different services, work independently and parallel to each other and are financed through diverse mechanisms.

Social Security institutions provide services to nongovernment employees and their families through the IMSS, and for government employees (and families), the Institute of Social Services for State Employees, ISSSTE is the main provider.

SEGURO POPULAR is an income-based health care insurance, introduced in 2003 by the Ministry of Health, available to all non-salaried workers who cannot access social security because they do not have an employer. It includes independent workers, as well as those who do not participate in the labor force (i.e., homemakers and elderly people, etc). This institution provides financial protection for more than 50 million Mexicans, and is improving access to health services and reducing the prevalence of catastrophic and impoverishing health expenditures, especially for the poor. A small subset of the population is covered by private insurance. Important differences can be observed between the benefits received by individuals affiliated with the social security institutions and those offered through Seguro Popular $[12,13]$.

According to the latest census in 2010, the percentage of the population that reports as having health insurance has increased to $64.55 \%$ (33.8\% are uninsured). Most of the increase has been the result of the introduction of Seguro Popular, which represented $36.1 \%$ of the total number of insured citizens as reported in the census. The other two main social security institutions, IMSS and ISSSTE, represent coverage of $48.8 \%$ and $9.9 \%$ of the total, respectively, while private insurance has decreased to $2.3 \%$ of the total (See Table 2).

A long-term care system aimed at care for the elderly is nonexistent at the federal level, and thus the states are left with the task and responsibility of choosing what services, if any, they provide. Scarce data is available on federal level programs caring only for older adults or on institutions attached to state level agencies, such as the state level 
Table 2 Healthcare coverage for the elderly in Mexico

\begin{tabular}{ll}
$\begin{array}{l}\text { Percentage of } \\
\text { elderly people } \\
\text { covered }\end{array}$ & Institution \\
\hline 53.4 & IMSS \\
28.1 & Seguro Popular \\
12.8 & ISSSTE \\
5.7 & Another institution \\
$72.6 \%$ & Total \\
\hline
\end{tabular}

consists of a monthly non-taxed allowance of approximately \$25 USD per older adult and its aim is to support families living in poverty. Participants are required to attend a bimonthly medical consultation in order to get the support. Finally, there is a national level initiative within the System of Social Protection in Health, provided through Seguro Popular. The main objective of the initiative was to ensure access to health services provided by public institutions, independent of beneficiaries' socioeconomic conditions and their current health status. In addition, it intends to decrease or eliminate out-of-pocket payments at the moment of receiving the services by establishing an annual prepayment fee for each family covered. The two lowest income brackets of the population are exempt from paying the annual family fee. The benefits package include 16 wellness components for men and women aged 60 years and older that cover diverse areas such as oral health, prevention and control of tuberculosis, and diagnosis of diabetes, hypertension and obesity [14].

Some state level initiatives have begun to be implemented, the first being the Pension Alimentaria, a part of the Food Support, Medical Attention, and Free Medicines Program in Mexico City. This is a non-contribution pension estimated to have reached $96 \%$ of all adults aged 70 years and older since its creation in 2001 . The pension is provided through an electronic card that can be used in most commercial establishments in the City. The amount of the pension has slightly increased since its creation and was budgeted in 2012 for an amount of approximately $\$ 70$ USD a month. In addition, the initiative includes medical visits for older adults aged 70 years and up who are physically unable to attend a clinic or health care center. Also, it aims to identify medical conditions and when needed, refers the person to medical services and informs the family members of this need. Given that these interventions for older adults were recently incorporated into broader government policies aimed at fighting poverty, it is too soon to know what their impact has been and thus, evaluation strategies should be incorporated now to achieve this end. However, they are recognized as a first effort to alleviate some of the main inequalities that render this population group especially vulnerable.

Within the private insurance sector, long-term care insurance schemes are now being offered but little is known about premiums, coverage and the total number of people insured through these options. Given the fact that these schemes are expensive, it appears they are only accessible to a small fraction of the total population.

\section{Institutionalization}

Currently, few public institutions are in place that can cater to older adults who are unable to care for themselves due to 
medical or mental health problems. There are some private institutions that offer daycare and institutionalization, performing a wide range of activities. In addition, the current legal framework seems extensive but does not enhance or regulate long-term care. Most laws from the Official Mexican Standard (Norma Oficial Mexicana) are directed towards medical ambulatory or hospital care for the ill and disabled, and only one is directly aimed at the provision of social services to children and the elderly [15]. Secondary laws and regulations are urgently needed in order to regulate standards of care and the institutions providing such services, public and private.

Most of the scarce public institutions belong to federal or state level INAPAM and DIF agencies. While INAPAM has a small number of residences that provide comprehensive care to the elderly who have no family support or financial resources to cover their basic needs, DIF provides care for elderly people in shelter homes and related nursing homes. In 2010, DIF reported four homes for the elderly, covering on average 470 individuals [16].

An increasing number of civil society organizations (nongovernmental organizations) have been created; many of them work on topics related to the aging population. These organizations perform a wide range of activities, including those supporting the interests of disabled and elderly individuals.

In terms of the total number of organizations or institutions providing long-term care for older adults, the lack of a national, state and local compulsory registration system implies that disaggregated data from various sources must be consulted, making it complicated to generate a "fullpicture" of long-term care institutions. Furthermore, it is not uncommon for data results to not coincide exactly among sources of information, possibly due to the use of different sector classifications. Few studies have been done in order to evaluate the quality of the institutions or the impact they have on older adults' wellbeing. The most relevant have concluded that the quality of services provided is unacceptable both in private and public institutions due to many factors, including unqualified or inadequately qualified personnel, inadequate infrastructure and unsafe conditions, among other issues. In addition, they point out the lack of an adequate normative framework and mechanisms of supervision as a problem and as a consequence of the increased rise in institutions providing inadequate or substandard care [17].

\section{Informal Care}

Currently, the majority of the older population lives at home with their spouse or partner, children, grandchildren or other close relatives. Here, most of the long-term care they need is provided to them and within this pool of family members, mostly by women. Nevertheless, reduced fertility rates, constant rural-urban migration within Mexico and international migration, women's increasing participation in the labor force and activities outside the home, among other factors, have changed family size and composition and pose future challenges to the availability of household care and support.

In terms of caregiver support, there are no special benefits such as tax incentives, monetary support or respite care for informal sector. For workers attached to a social security institution, leave schemes do not provide any special arrangements for family careers. Although there are some small studies on informal care and caregiver burdens, a country-wide study on caregiving for older adults and its associated burdens is urgently needed.

In spite of the major effort and burden of care being done at the household, studies of the health care system don't take these issues into account. 2010 was the first time that firsthand information was gathered on what informal nonremunerated household health care represents to the greater system. The Health Sector Satellite Account generated as part of the National Health Accounts shows that $19 \%$ of the Health Sector Internal was provided through nonremunerated health care provision $(36 \%$ public sector, $44.4 \%$ private sector). In addition, when this product is analyzed by type of goods or services, this $19 \%$ is almost equivalent to the $20.7 \%$ of hospital services, almost twothirds of ambulatory services (28.1\%), and represents more than double of what is spent on health care goods $(9.1 \%)$ [18].

\section{Geriatrics Education}

The creation of elderly health care providers is not enough, even with many small courses in geriatrics and gerontology that are part of the undergraduate medical curriculum in several universities, including the biggest and most relevant, UNAM (National Autonomous University of Mexico).

Currently in Mexico, there are approximately 400 hundred certified geriatricians. The first resident program in geriatrics was introduced in 1994. There are important differences among the education programs available for geriatricians, a situation that likely contributes to differences in the opinions and practices of doctors and clinicians in this specialty. By August 2010, seven universities from Mexico had begun offering the geriatric specialization, with less than $70 \%$ of the specialty slots taken. In addition, this track of medical practice includes subspecialties in cardiogeriatrics, dementia, neurogeriatrics and rehabilitation. Considering the most conservative recommendations, over the next ten years Mexico needs to graduate 2,019 geriatricians, close to 200 each year, to meet projected health 
care needs. Obviously, the current rate of preparation is insufficient.

Mexico has more than 30 locations specializing in geriatrics services, most of them located in Mexico City as part of larger hospital operations; there are also a few more specialized geriatric services, also located in Mexico City (such as three memory clinics, one cardiogeriatric service, and one geriatric rehabilitation department) [19].

\section{Instituto Nacional De Geriatría}

The National Institute on Aging (Instituto Nacional de Geriatría, INGER) was created in 2008 as a result of the need to produce more geriatricians, and specializes in developing human resources dedicated to elderly care. INGER contributes to improving national policies on aging and age research and the creation of health care systems accords to the needs of the aging country.

Through its coverage area the institute focuses on biological aging mechanisms - society, aging and economy-as well as clinical and epidemiological geriatrics and gerontechnology, which have been demonstrated and publicized in different global scenarios. Also, two years ago the institute promoted the creation of the Specific Aging, Health and Social Developing Net (ESDS), which has almost 150 researchers focused in specific areas, from different institutions around the country.

In addition, the institution investigates health care systems within Mexico, primarily in terms of the varying levels of medical attention (urgency, acute elderly care, primary care, telemetry, etc.). All this research has been developed in conjunction with different public, private and academic, national and international institutions.

There is a constant growth in the development of clinical guidelines with a strong evidence-based frame, with two first titles upcoming next autumn: "Sarcopenia: diagnosis and treatment in primary care" and "Physical performance assessment in the elderly for primary care physicians".

Another principal area of contribution from the Institute is teaching and knowledge translation dedicated to elderly attention and care; a current project underway is the construction of an extensive human resources network. This project has been named FORHUM3 (human resources training), because it is a triple alliance program. In addition, the Institution is building a virtual library focused specifically on aging and age.

In the next five years, the Institute will focus on development, operations and the evaluation of a new elderly health care system and gerontological/geriatric education, with a strong evidence-based perspective. In addition, it will continue the development of biological, clinical, technological and biomedical research.

\section{Conclusions}

The shift in the Mexican demographic is becoming more apparent, with an increasing number of elderly subjects having functional dependence and chronic diseases. However, the socioeconomic context may be the main problem in this population. Currently, public services provided for the older population lack knowledge on health and social care services that could be provided in anticipation of and as preventative strategies for their future needs. In addition, there is no clear or comprehensive information on services provided by the private sector, much less their quality and efficiency, or the impact they have on the wellbeing of this population group. In addition, a rapidly aging population and the absence of formal support services for the elderly has left informal caregivers, mostly women, with the main responsibility of providing household care activities through the life cycle, from early childhood care and family health care, to health and long-term care services for the elderly. Although this lack of strategies for the older population has not yet created huge crises in terms of the provision and financing of services, presumably in large part due to the support of the family and social networks of the elderly, a large increase in their numbers will at least cause a significant additional burden on households and on available services.

Mexico should build programs and policies with a humans rights perspective that are oriented to:

1. Adapting the elderly health care system to new older adults' needs, focused in primary care, oriented to avoidance of functional dependence and enhancing active and healthy aging, with an adequate information system;

2. Training specialized medical professionals dedicated to the care of elderly people;

3. Producing adequate data to develop and evaluate programs and services;

4. Generating mechanisms to an optimum interinstitutional cooperation, specially in terms of socio-sanitary and human resources collaboration, formation;

5. Including the age perspective in any public policy and program [20]

On the other hand, Mexico does not have a national social care system or a long-term care policy to integrate, regulate and evaluate all social and personal care facilities, including long-term care facilities. Unfortunately, neither health nor social development institutions have made the effort to regulate or generate norms that govern these institutions; most of the ones that are known are characterized by their small and informal nature and there is no real way to know if they are covering the standards required for appropriate social care for the people that live in them. It is also clear that great efforts should be made in order to generate a 
directory of existing institutions, and to generate from this data in depth evaluations of their services and their impact on the wellbeing of their beneficiaries.

Given the current scarcity of integral governmental strategies for health and social care for the elderly in Mexico, and the little information available on private (for-profit and not-for-profit) institutions the type and quality of the services they provide, and on the population they are serving, it is clear that health, social security, and social development ministries, who have historically tried to compensate with alternative or palliative care provisions for the older population, are largely unprepared to address the needs of the growing elderly population.

Even federal institutions or ministries that have social care institutions (targeted at all ages or specific vulnerable groups) don't conduct comprehensive monitoring and evaluation of these facilities and when they do report some information, they limit their investigation to asking respondents only basic questions about the services they receive. In addition, the current recommendations from several federal and state level ministries are centered on the generation of general laws and regulations for all institutions providing temporary and long-term care for older adults. Urgent reforms are needed in order to put in place comprehensive long-term care policies and a social care system that integrates all existing atomized efforts, regulates them and allows for monitoring and evaluation of their overall quality and impact on residents' wellbeing.

Disclosure No potential conflicts of interest relevant to this article were reported.

\section{References}

1. Instituto Nacional de Estadística y Geografía, INEGI. Censo de Población y Vivienda 2010, CONAPO 2010.

2. Ham Chande R. Old adults in Mexico. Sociodemographic profile at the beginning of XXI century. In: Demography. INEGI, México. 2012. Accessed 01/02/2012 2012.
3. Division. ODfEIaA. Health Data 2012. In: Health Policies and Data. http://www.oecd.org. 2012.

4. Torres-Arreola Ldel P y Villa Barragán JP. Consideraciones sobrel el envejecimiento género y salud. En: Envejecimiento Humano: Una Visión Transdisciplinaria. Instituto de Geriatría. Secretaria de Salud. 2010.

5. SSA. http://www.sinais.gob.mx. 2012.

6. Barrantes-Monge M, Garcia-Mayo EJ, Gutierrez-Robledo LM, Miguel-Jaimes A. Functional dependence and chronic disease in older Mexicans. Salud Publica Mex. 2007;49 Suppl 4: S459-66.

7. Mejia-Arango S, Gutierrez LM. Prevalence and incidence rates of dementia and cognitive impairment no dementia in the Mexican population: data from the Mexican Health and Aging Study. J Aging Health. 2011;23(7):1050-74. doi:23/7/1050 [pii].

8. Encuesta Nacional de Nutrición y Salud. 2006.

9. Andrade F. Estimating diabetes and diabetes-free life expectancy in Mexico and seven major cities in Latin America and the Caribbean. Rev Panam Salud Publica. 2009;26(1):9-16.

10. Camposortega S. Cien años de mortalidad en México. En: http:// www.ejournal.unam.mx/dms/no10/DMS01005.pdf 1997.

11. Federal E. Informe al Ejecutivo Federal y al Congreso de la Unión 2010-2011. In: SSA, editor.2011

12. Knaul FM, Gonzalez-Pier E, Gomez-Dantes O, Garcia-Junco D, Arreola-Ornelas H, Barraza-Llorens $\mathrm{M}$ et al. The quest for universal health coverage: achieving social protection for all in Mexico.

13. Frenk J. La salud como derecho ciudadano. Nexos. 2012.

14. Comisión Nacional de Protección Social en Salud. Catálogo Universal de Servicios de Salud. 2008

15. SSA. NOM 167 SSA1 1997 Norma oficial para prestación de servicios de asistencia social para menores y adultos mayores. In: SSA, editor.1997.

16. INAPAM. http://www.inapam.gob.mx/; http://www.dif.gob.mx/ diftransparencia/media/grupos/ancianos/centromayores.html. 2010.

17. Gutierrez-Robledo LM, Reyes-Ortega G, Rocabado-Quevedo F, Lopez-Franchini J. Evaluation of long term care institutions for the aged in the Federal District. A critical viewpoint. Salud Publica Mex. 1996;38(6):487-500.

18. Sistema de Cuentas Nacionales de México: Cuenta satélite del sector salud de México, 2008-2010 / Instituto Nacional de Estadística y Geografía. INEGI, c2011.

19. Ávila-Fematt FM. La enseñanza de la geriatría en México. In: Gutierrez-Robledo LM, editor. Envejecimiento y Salud: Una propuesta para un plan de accion. Mexico: Universidad Nacional Autonoma de Mexico; 2012. p. 287-302.

20. Gutierrez-Robledo LM, Kershenovich D, editors. Envejecimiento y Salud: Una propuesta para un plan de accion. Mexico: Universidad Nacional Autonoma de Mexico; 2012. 